\title{
A cohesive model to predict the loading bond capacity of repaired/reinforced concrete structures stressed to mixed mode
}

\author{
V. Savino ${ }^{\mathrm{a}}$, L. Lanzoni ${ }^{\mathrm{b}, \mathrm{c}}$, A.M. Tarantino $^{\mathrm{b}, \mathrm{c}}$, M. Viviani ${ }^{\mathrm{a}}$ \\ ${ }^{a} H E S-S O$ / HEIG-VD - Haute Ecole d'Ingénierie et de Gestion du Canton de Vaud, \\ Route de Cheseaux 1, CH-1401 Yverdon \\ ${ }^{b}$ DIEF-Department of Engineering "Enzo Ferrari", University of Modena and Reggio \\ Emilia, 41125 Modena, Italy \\ ${ }^{c}$ CRICT - Centro Interdipartimentale di Ricerca e per i Servizi nel Settore delle \\ Costruzioni, via P. Vivarelli 10, 41125, Modena, Italy
}

\begin{abstract}
The risk of cracking/debonding of a cement overlay used to repair or strengthen an existing structure is still a key issue. Current bond test methods are not designed to measure the combined effect of peeling (mode I) and shear (mode II) on the interface. A few existing models propose theoretical approaches to predict that, but they were fitted on specific cases and lack in generality. In addition, controversial opinions about the influence of both the moisture level of the substrate surface prior to the application of the overlay and properties of the latter on the loading bond capacity call for further investigations. In this work, a cohesive model is developed to predict the loading bond capacity of an existing concrete structure overlaid by a layer of HPFRC/UHPFRC. Different bond tests were specifically designed for calibrating the cohesive parameters employed into the model, which also takes into account the type of the overlay used and the moisture conditioning level. An experimental campaign confirmed the reliability of the predictions of the proposed theoretical model.
\end{abstract}

Keywords: Metal-matrix composites; Mechanical properties; Damage mechanics; Mechanical testing; Interfacial stresses

Email address: luca.lanzoni@unimo.it (L. Lanzoni) 


\section{Introduction}

An increasing number of industrial applications of HPFRC (High Performance Fibre Reinforce Concrete) as repairing material on deteriorated structures has been observed in recent year [16, 29]. This is not the case for UHPFRC materials (Ultra High Performance Fibre Reinforce Concrete), despite their higher performances in terms of strength, ductility and durability [13, 40, 41, 42. Among the reasons underlying the lower interest to use UHPFRC in the field of the civil engineering there are both the high manufacturing cost and the missing harmonization of existing codes. Nevertheless, recent applications have successfully involved the use of UHPFRC both as new materials (e.g. beam, panel manufacturing, etc.) 67] and as overlay material for rehabilitating and strengthening bridge decks [11, 26] and hydraulic structures [25, 39]. As far as the properties of a fiber-reinforced overlay material could be excellent, if the substrate preparation and pouring operations of the overlay are not well designed, the risk of bond failure could be high. In the practice of retrofitted concrete structures, the bond failure is caused by both the different physical properties between substrate and overlay (thermal expansion coefficient, elastic modulus, etc.) and external loadings [22]. For both cases, the cracking/debonding along the interface is related by several aspects like the fracture energy magnitude and the shape of cohesive law governing the interface response. HPFRC/UHPFRC overlays might therefore reduce the risk of cracking/debonding, since they provided high bond strength and good adherence to the concrete substrate members, as observed in previous works [1, 27, 48]. This effect is also related to the presence of steel fibers within the HPCC/UHPC matrix that transmit the force through the cracks in the matrix ${ }^{1}$, thus the built-in peak stress ${ }^{2}$ at the interface decreases, which reduces the risk of premature cracking/debonding [23. Further improvements of bond strength can be achieved by installing a series of dowel bars properly anchored both in the substrate and in the overlay, even though the reinforcement has to be deformed plastically prior

\footnotetext{
${ }^{1}$ The advantages offered by the use of synthetic fibers to realize FRC elements are discussed, as an example, in 30, 38.

${ }^{2}$ In the field of contact problems the different physical properties between the substrate and overlay (thermal expansion coefficient, elastic modulus, etc.) tend to create internal forces, stresses and strains along the interface prior to application of external loads. The cracking/debonding at the interface is in part the consequence of the increase of built-in (internal) stresses [24, 53].
} 
to carry a relevant part of the load. Since they are more rigid than the overlay, they will carry the load only after the bond breaks [46]. This solution, even if increases the global capacity of the bond, does not prevent a premature deterioration of the interface. A premature cracking/debonding can be avoided also by both a correct testing of the bond loading capacity [52] and a subsequent accurate structural design [12, 14, 15].

\subsection{Influence of the substrate preparation prior to overlay on bond strength}

The soundness and roughness of the substrate strongly influence the bond strength development. Both parameters seem to depend on the removal methods of the deteriorated concrete [8, 46], like impact, high pressure water, or mixture of them. The impact methods are based on the use of breakers to fracture and spall the unsound concrete. Rougher surfaces of the interface are provided, which is beneficial to the bond strength [37]. But the heavy impact performs micro-cracks on the concrete surface [21, 54]. Another removal method used in the practice is the hydro-jetting. Hydro-jetting disintegrates unsound or deteriorated concrete and ensures a substrate with a sound and rough surface profile. Hydro-jetting provides a less pronounced roughness profile than impact methods, but no micro-cracks are observed [37]. Nevertheless, Kauw and Dornbusch (1997) [28] and Silfwerbrand (2000) [43] concluded that a minimal compressive strength of the substrate is requested to avoid the rupture of sound concrete as well, as also confirmed by Bissonnette at al. (2008) 8]. Findings of Silfwerbrand (1990) [44 showed that a roughness surface profile provided by sandblasting leads to maximum gains of tensile bond strength. Also the moisture condition of the concrete substrate surface prior to overlay plays a key role on the development of the bond strength, even though such a phenomenon is still controversial. In fact, Beushausen (2010) [5] and Vaysburd et al. (2016) [50] stated that a "dry" substrate condition prior to overlay leads to better performances of the bond than "saturated-surface-dry" (SSD) conditions; in certain cases, SSD treatment was even detrimental. De la Varga et al. (2015) [49] and Lukovic and Ye (2016) [36] claimed that SSD condition provides the best bond strength. Bissonnette et al. (2014) 9] suggested that the optimal saturation level ranges from $55 \%$ to $90 \%$.

\subsection{Influence of test methods on bond strength}

Current specifications in the concrete repair technology suggest that bond strength is defined as the tensile strength measured at the interface (mode 
I) via "pull-off" tests [56, 57]. However, test results can be affected by both eccentricity in the load application and damage during the coring. A solution can be found by using a "direct tension" test 35. Both tests are limited to the fact that if the bond strength is higher than tensile strength of bonded materials, the failure will not be at the interface, and recorded data will be useless. In many practical cases the interface is subjected to pure tension only at the small zones close to edges. By contrast, shear stresses (mode II) occur along the entire interface, e.g. in composite slabs subjected to bending loads. For this reason, shear test methods have been developed as well [45, even though none of these has been accepted as standard. The "slant shear" test is the most used; the set-up is easy, the reliability of the results is good. Nevertheless, unrealistic loading conditions are applied to the interface. The failure of the interface depends on the angle of the plane with respect to the load ${ }^{3}$. In addition, the test is relatively insensitive to the surface preparation and roughness, since bond failures occurred only for smooth surfaces [2, 17]. A more realistic loading condition is reproduced via "lateral shear" tests, but the presence of a bending moment at the interface, due to the shear force eccentricity, promotes the development of peeling stresses which affect the shear strength. In order to prevent such an inconvenient, Silfwerbrand (2003) 45. developed a "twist off" test, although, according to the theory of brittle material strength, the failure plane is not parallel to the torque plane, but it has an inclination around 45 degrees. In the case of bonded materials subjected to the torsion torque, the plane of failure does not correspond with the plane of the interface. In fact, experimental results in [7, 45] confirmed such geometric incompatibility. A different test method, named "direct shear", solved the problem of geometrical incompatibility observed in the twist-off test. In addition, the fact that the load shear was directly transmitted along the interface permitted to reduce the bending moments and tensile forces arising at the interface [6].

In the practice, cracking/debonding between substrate and overlay propagates in a mixed mode of stresses at the interface [24]. Such an aspect is not properly taken into account by current test methods, which could overestimate the bond capacity. Only one concerning investigation was found in Literature [2]. In such a work authors attempted to define an empirical bond

\footnotetext{
${ }^{3}$ Various works can be found in Literature devoted to damage mechanics. In the framework of finite elasticity, some recent studies are proposed in [32, 33, 34, 47.
} 
failure envelope concept for normal concrete repairs, by supplementing pulloff and slant-shear data results. But, as also discussed above, slant shear method proved to have serious shortcomings, as few cases of bond failure were recorded. In the lack of data, few existing models propose theoretical approaches to predict the mixed mode behavior, but they were fitted on specific cases and lack in generality 24 .

The aim of this work is to develop a cohesive model able to predict the loading bond capacity of retrofitted concrete structures . In particular, the model can predict the load-slip behavior of bonded materials subjected to mixed mode stresses, by taking into account both the moisture conditions of the substrate prior to the application of the overlay and the properties of the latter. The relationships for mode I, mode II and their coupling factor were calibrated according to bond tests specifically designed by authors. An independent experimental investigation permitted to validate both the proposed model and highlight the different cracking/debonding patterns observed in the system "overlay-interface-substrate" by changing the properties above discussed. In order to properly reproduce the rehabilitation in the practice, the hydro-jetting method was adopted for preparing the substrate prior to overlay. The roughness profile was carefully analyzed. A description of the experimental program is provided in Section 2; in Section 3 the experimental results are discussed; in Section 4 the cohesive model is presented and theoretical results are compared with the experimental data; finally, conclusions are drawn in Section 5 .

\section{Materials and Methods}

In order to characterize the loading bond capacity of retrofitted composite concrete structures, several concrete slabs were cast, exposed to weather conditions for 90 days and then subjected to the surface treatment by hydrojetting. The roughness profile of the surface was measured by photo-scanning. Then, the substrate was prepared to the application of the overlay. Two commercial fiber-reinforced-concretes were used as overlay, one HPFRC and one UHPFRC. After 28 days of curing, the specimens were prepared and tested. Details of material and methods are presented in the following subsections.

\subsection{Substrate}

The substrate was manufactured using a commercial self-compacting concrete (SCC) reinforced by steel bars. Both concrete and steel are compliant 


\begin{tabular}{lccc}
\hline Properties & Substrate & Overlay A & Overlay B \\
Maximum aggregate size $(\mathrm{mm})$ & 16 & 6 & 2 \\
w/c & 0.4 & 0.28 & 0.17 \\
Slump test $(\mathrm{mm})$ & $700^{(\mathrm{a})}$ & $240^{(\mathrm{b})}$ & $250^{(\mathrm{b})}$ \\
Slump test T500 (mm) & - & $60^{(\mathrm{c})}$ & $517^{(\mathrm{c})}$ \\
Compressive strength $(\mathrm{MPa})$ & $59 \pm 3.3^{(\mathrm{d})}$ & $78 \pm 3.1^{(\mathrm{d})}$ & $147 \pm 5.3^{(\mathrm{d})}$ \\
Tensile strength $(\mathrm{MPa})$ & $2.9^{(\mathrm{e})}$ & $6.5 \pm 0.9^{(\mathrm{f})}$ & $14.6 \pm 1.12^{(\mathrm{f})}$ \\
Modulus of Elasticity (MPa) & $35000^{(\mathrm{g})}$ & $38300 \pm 200^{(\mathrm{h})} 47100 \pm 200^{(\mathrm{h})}$ \\
\hline
\end{tabular}

According to 64](a), 63](b), 65](c), 66 (d), 61](e), 58](f), 59](g), 62 (h).

Table 1: Fresh and hardened material properties

with the Swiss standards and largely used to build slabs on grade, bridge decks and pavements. The material properties of SCC are reported in Table 1. Thirty slabs of SCC were cast. Twelve $150 \mathrm{~mm}$ cubes of SCC were made as well, in order to determine the compressive strength of the substrate, which is fundamental to estimate the adequate water pressure magnitude of hydro-jetting, see Section 1.1. The geometry of the specimens differs from one another, according to the corresponding test configuration, see Section 2.4 and Fig. 1.

In order to consider the effect of different environmental conditions on existing concrete members, concrete slabs were cast outdoors, both in summer and winter (Switzerland). The environmental conditions, during the casting, were $24{ }^{\circ} \mathrm{C}$ and $74 \% \mathrm{RH}$ and $7{ }^{\circ} \mathrm{C}$ and $87 \% \mathrm{RH}$, in summer and winter respectively. After molding, concrete slabs were covered by a plastic sheet and cured in the lab under constant environmental conditions $\left(23 \pm 2^{\circ} \mathrm{C}, 55 \% \pm 5 \%\right.$ $\mathrm{RH})$. After 28 days of curing, concrete slabs were demolded, placed outdoors and exposed to weather conditions (sun, wind, rain, snow) for additional 90 days, both in summer and in winter (Switzerland).

\subsection{Treatment prior to overlay}

After 90 days of external exposition, the upper surface of slabs was removed by using a 2500 bars hydro jetting machine. In order to calibrate the adequate water pressure to hydro jet the concrete slab surface, see Section 1.1. compressive tests at 28 days were carried out on cubic specimens according to European standards [66]. Cubic specimens - which were made of the same compounds of concrete slabs - and slabs were cast simultaneously. Cubic specimens were demolded after 3 days from casting and cured in the lab 


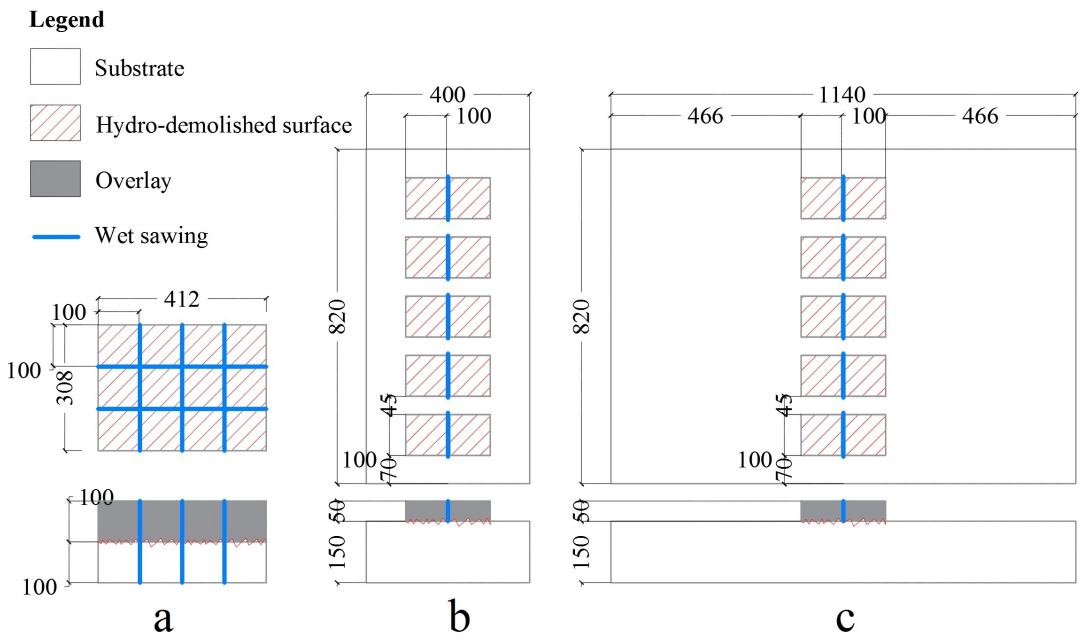

Figure 1: Specimens for a): direct shear and direct tensile tests; b): pull-off test; c): tension/shear and lateral shear tests

under constant environmental conditions until the day of compressive test. Practical observations suggest that a proper hydro-jetting can be achieved when the ratio between water pressure and compressive strength of the substrate ranges from 2.5 to 3.5, for a standard distance between the nozzle and the concrete surface. Since the compressive strength of SCC was $59 \pm 3.3$ $\mathrm{MPa}$, water pressure was set to 1800 bars. A concrete layer of $50 \pm 10 \mathrm{~mm}$ was removed by hydro-jetting. The resulting surface was rough and sound, as confirmed by a visual examination, see Fig. 22. A photogrammetric method was adopted for measuring the roughness profile. A commercial software was adopted for processing digital images and generates 3D spatial data of the scanned surfaces. Processed data provide the roughness altitude in 4 points per square millimeter. Since the interface area of each specimen was $100 \times 100 \mathrm{~mm}^{2}$, a population of 40000 points was used to calculate the average roughness and the standard deviation.

Once roughness profile of the interface was scanned, the substrate was prepared to the application of the overlay. In order to quantify the influence of substrate moisture states on the bond strength, the whole range of possible moisture conditions was taken into account, in particular dry, $75 \%$ and SSD. Dry-type surface was reached by curing the substrate surface for 14 days at laboratory conditions of $23 \pm 2^{\circ} \mathrm{C}, 55 \% \pm 5 \% \mathrm{RH}$, as also seen in [3]. During the curing, surface substrate was covered with a plastic sheet, in order to 


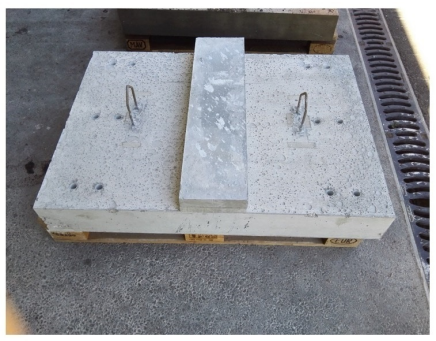

a

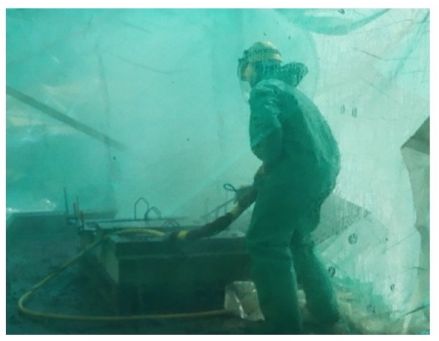

b

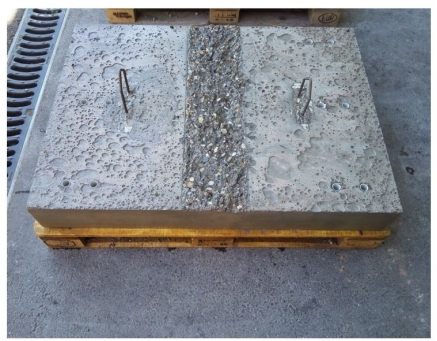

C

Figure 2: a): specimens before hydro-jetting; b): hydro-jetting operation; c): specimens after hydro-jetting

slow down the carbonation process. $75 \%$ and SSD conditions were achieved by keeping wet the substrate surface for 24 hours, then surface was manually dried with towels to attain the SSD conditions. Several hours later, at laboratory conditions, a moisture level of $75 \%$ was reached. The surface moisture level was measured by a superficially encased relative humidity probe. The digital probe signal is processed by a multifunction hand-held indicator. It provides temperature, $\mathrm{RH}$ and time of measure.

\subsection{Application of the overlay}

The moisture level of the substrate prior to the application of the overlay is not the only parameter that affects the development of the bond strength. The ability to increase the density of the interfacial zone, which leads to better bond, also depends on both the water movement contained in the overlay (w/c ratio) and the capacity of the fresh overlay material to flow and fill cavities of the roughened substrate surface. In order to better understand the influence of both w/c ratio and fluidity of the overlay on the bond strength, two commercial overlay materials, with different properties, were used for this purpose. One of them was a HPFRC, labeled here after overlay A, the other one was a UHPFRC, labeled here after overlay B. The material properties are listed in Table 1. Mix design is listed in Table 2. Further details of mixing are reported in [40]. Once the desired moisture conditioning of the substrate was achieved, overlay was manually poured and compacted. The overlay was covered by plastic sheets and cured in the lab under constant environmental conditions for additional 27 days. Then, specimens were demolded and divided in two or more items, in order to extend the number of specimens, see Fig. 1 . 


\begin{tabular}{lcc}
\hline & $\mathrm{kg}$ in $1 \mathrm{~m}^{3}$ of composite \\
Compounds & Overlay A & Overlay B \\
\hline Premix (cement, silica fume, sand) & 2135 & 1970 \\
Water & 230 & 195 \\
Superplasticizer & 21.3 & 39 \\
Hooked steel fibers $30 / 0.6 \mathrm{~mm}$ & $25(0.3 \%)$ & - \\
Straight steel fibers $13 / 0.175 \mathrm{~mm}$ & - & $296(3.8 \%)$ \\
\hline
\end{tabular}

Table 2: Mix design of overlays

\subsection{Test methods}

An overview of the available bond test methods was reported in Section 1.2. To properly characterize the bond capacity of repaired concrete structures, the interface of the specimen was tested to realistic load conditions, which include pull-off, direct tensile, direct shear and tension/shear. The core pull-off test is considered the most common method for evaluating the bond tensile strength in the field [51]. In this study a modified pull-off testing equipment was developed. As the device was load controlled, the post-cracking response of the interface could not be detected. However, a couple of LVDT were placed on both sides of the specimen, in order to measure both the initial stiffness and the opening crack corresponding to the peak of tensile bond strength. Such data were used to calibrate some key cohesive parameters of mode I, see Section 4. LVDT measures a range of displacement detected within the system "substrate-interface-overlay" subjected to pull-off loads, which does not encompasses just the opening crack arising along the interface, but also the deformation of bonded materials. This drawback was therefore minimized, since the majority of the deformability of the system was at the interface, as confirmed by measuring both the initial stiffness and the peak of strength observed in Fig. 5, which are much lower than those of bonded materials, see Table 1. The testing equipment includes a cylinder which transfers the tensile load to the interface surface. The pressure in the cylinder is provided by a lightweight hand pump. Since the pull-off strength estimation improves as loading rate slows down [10], in this investigation the loading rate was set to $0.003 \pm 0.002 \mathrm{MPa} / \mathrm{s}$, which is much lower than standard suggestions [60]. A load cell, set-up on the cylinder, detects the loading rate, with an accuracy of $2 \%$. A pin system fixed to the head of the specimens (overlay) was designed in order to prevent the effect of load eccentricity at the interface. The modified pull-off test is 
illustrated in Fig. 33. A series of specimens was also tested to direct tensile stresses (Fig. 3b), to confirm the reliability of the modified pull-off test. A displacement controlled computerized universal testing machine was used to carry out direct tensile tests. Details of testing machine were discussed in [40. In order to observe the post-peak behavior, which could not be detected in pull-off tests, a strain rate was used to pilot direct tensile tests. With the aim of having comparative rates between modified pull-off and direct tensile tests, the opening crack rate was set to $0.07 \pm 0.01 \mathrm{~mm} / \mathrm{min}$.

If for tensile tests is possible to transfer a pure stress on the interface (mode I), things are different when shear stress (mode II) is demanded. The disadvantage of most common shear methods is the occurrence of a bending moment due to the shear force eccentricity applied at the interface, as already discussed in Section 1.2. In this work, such a problem was faced by adopting a direct shear configuration test, as also seen in [6]. Specimen dimensions were the same of those tested in tensile series, in order to avoid the influence of size effects. A displacement controlled computerized universal testing machine was used to carry out direct shear tests. A slip rate of $0.07 \pm 0.01 \mathrm{~mm} / \mathrm{min}$ was set. Four loading/supporting rollers transmit a direct shear load along the interface. Since the roughness profile provided by hydro-jetting is irregular and slightly different from one specimen to another, a proper position of loading/supporting rollers is fundamental for reducing the risk of load eccentricity. For this reason the loading/supporting rollers are not fixed, they can move in order to minimize such a risk, for each test, see Fig. 35.

In the practice, the unbalanced shear stresses near to discontinuities of the bonded overlay (e.g. slab edge, cracks, joint) leads to the development of tensile stress, perpendicular to the interface. As consequence, a peeling moment is generated and increases with the edge overlay thickness [22]. In order to reproduce this stress condition (mixed mode), which can generate a cracking/debonding failure at the interface, a lateral shear device was developed ,see Fig. 3d. Since the cracking/debonding failure usually begins near the discontinuities of the bonded overlay, the specimen length was defined to represent the edge of this critical region. The specimen size was defined also by taking into account the limited load carrying capacity of the testing system, which is man-portable and it can be easily set-up both in situ and in the lab. A couple of gauge was placed on both sides of the specimen for measuring the average slip at the interface. The testing equipment includes a cylinder which transfers the shear load to the interface. The pressure in 


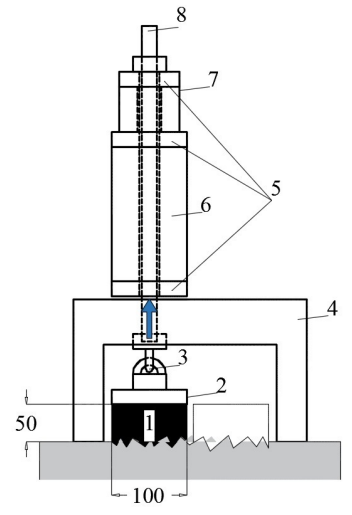

a

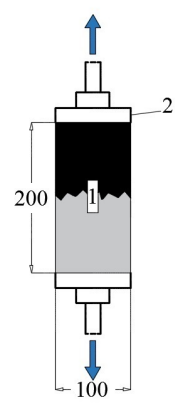

b

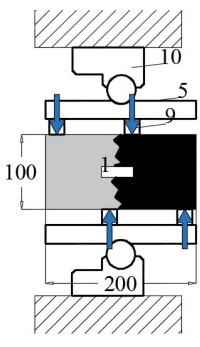

c

\section{Legend}

1: LVDT

2: steel plate glued to the specimen

3: pin system

pulloff device

bearing plates

cylinder (tensile loading)

force transducer

steel rod

support/loading roller

pin-fixed device

1: cylinder (lateral loading)

12: force transducer

13: rigid support

14: sliding support

concrete substrate

concrete overlay

Figure 3: a): Pull-off test; b): Direct tensile tests; c): Direct shear test; d): Lateral shear test; e): Tension/shear test

the cylinder is provided by a lightweight hand pump. The loading rate was set to $0.003 \pm 0.002 \mathrm{MPa} / \mathrm{s}$, in order to have comparative results with the pull-off tests. The load cell, fixed to the cylinder end, detects the loading rate, with an accuracy of $0.8 \%$.

In order to measure the coupling factor between mode I (peeling-crack) and mode II (shear-slip), a tension/shear bond test method was developed, by coupling the lateral shear with the modified pull-off devices presented above. The interface is subjected to a fixed tensile load, while shear load increases until the bond failure, see Fig. 33. By varying the loading ratio is possible to encompass all possible tension/shear stress states encountered in the practice. The stress rate was set to $0.003 \pm 0.002 \mathrm{MPa} / \mathrm{s}$ to have comparative results with pull-off and lateral shear tests. Experimental results of tests presented above were recorded on a data acquisition software, with a frequency of $10 \mathrm{~Hz}$. 


\section{Experimental results}

Specimens tested in this investigation were labeled according to the type of test carried out, type of overlay and moisture condition level of the substrate prior to overlay. In particular:

- P, DT, DS, LS, TS: stand for pull-off, direct tensile, direct shear, lateral shear and tensile/shear test;

- Dry, 75, SSD: stand for dry substrate, moisture surface level of $75 \%$ and saturated-surface-dry;

- A, B: stand for overlay A (HPFRC) and overlay B (UHPFRC).

By varying the parameters above, thirty series were investigated, each of these was composed by 8-10 specimens. In the following, due to the large amount of data recorded, just some representative results will be illustrated.

\subsection{Roughness profile of the interface}

After hydro-jetting, the surface profile of the substrate prior to the application of the overlay was analyzed via photogrammetric processing, as discussed in Sections 2.2. Fig. 4 shows an example of roughness profile investigated. The colored area represents the interfacial zone of the substrate prior to the application of the overlay. For each series, statistical analysis of roughness profile were computed. Results showed agreement with [37]. Table 3 lists results recorded for a given series.

\begin{tabular}{ccccc}
\hline Interfacial zone & $\begin{array}{c}\text { Minimum } \\
(\mathrm{mm})\end{array}$ & $\begin{array}{c}\text { Maximum } \\
(\mathrm{mm})\end{array}$ & $\begin{array}{c}\text { Average } \\
(\mathrm{mm})\end{array}$ & $\begin{array}{c}\text { Stand. Dev. } \\
(\mathrm{mm})\end{array}$ \\
TS-75-_1 & 139.1 & 157.1 & 150.2 & 3.13 \\
TS-75-_2 & 135.7 & 154.0 & 143.6 & 3.16 \\
TS-75-_3 & 136.3 & 156.5 & 145.9 & 3.82 \\
TS-75-_4 & 136.4 & 155.0 & 147.2 & 3.90 \\
TS-75-_5 & 137.3 & 156.5 & 146.8 & 3.22 \\
TS-75-_6 & 136.9 & 153.6 & 145.7 & 3.19 \\
TS-75-_7 & 134.5 & 151.9 & 143.1 & 3.05 \\
TS-75-_8 & 135.2 & 156.0 & 144.3 & 3.17 \\
TS-75-_9 & 139.2 & 154.0 & 146.3 & 2.81 \\
TS-75-_10 & 141.2 & 155.6 & 147.4 & 2.89 \\
\hline
\end{tabular}

Table 3: Logged roughness profile for a given series 


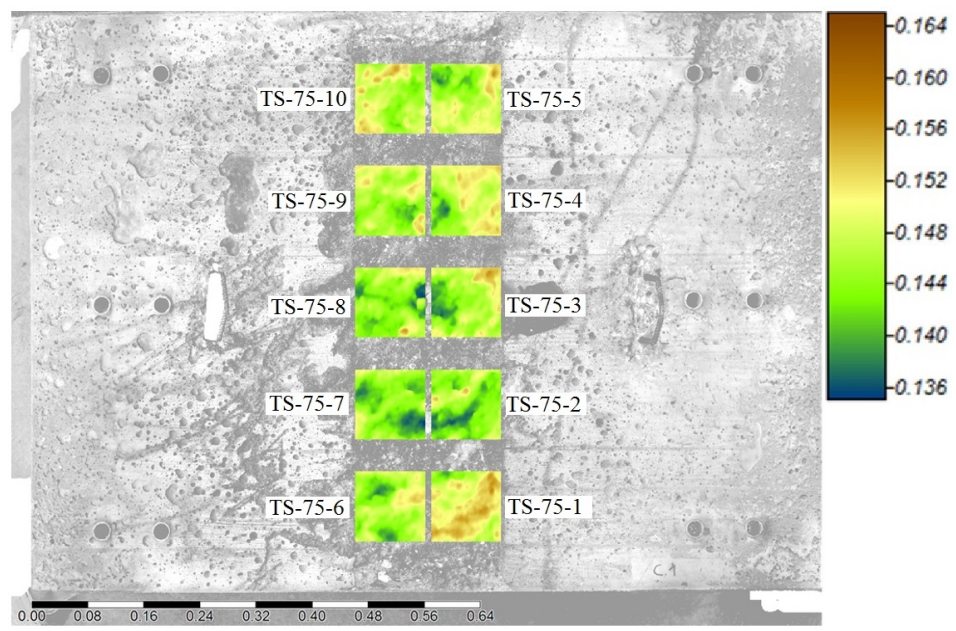

Figure 4: Roughness profile scanned for a given series (measuring in meters)

\begin{tabular}{ccccc}
\hline Series & \multicolumn{2}{c}{ Overlay A } & \multicolumn{2}{c}{ Overlay B } \\
& $q_{\max } / \tau_{\max }$ & $v\left(q_{\max }\right) / u\left(\tau_{\max }\right)$ & $q_{\max } / \tau_{\max }$ & $v\left(q_{\max }\right) / u\left(\tau_{\max }\right)$ \\
& $(\mathrm{MPa})$ & $(\mathrm{mm})$ & $(\mathrm{MPa})$ & $(\mathrm{mm})$ \\
P-dry & $1.6 \pm 0.15$ & $0.007 \pm 0.002$ & $1.62 \pm 0.28$ & $0.007 \pm 0.001$ \\
P-75 & $2.06 \pm 0.27$ & $0.008 \pm 0.002$ & $2.47 \pm 0.25$ & $0.008 \pm 0.001$ \\
P-SSD & $2.38 \pm 0.18$ & $0.009 \pm 0.001$ & $3.1 \pm 0.39$ & $0.008 \pm 0.001$ \\
DT-dry & 1.3 & 0.002 & 3.24 & 0.004 \\
DT-75 & 1.64 & 0.002 & 3.4 & 0.005 \\
DT-SSD & 1.49 & 0.002 & 3.45 & 0.006 \\
DS-dry & $7.09 \pm 0.68$ & $0.009 \pm 0.001$ & $5.77 \pm 1.29$ & $0.002 \pm 0.001$ \\
DS-75 & $5.57 \pm 0.55$ & $0.005 \pm 0.003$ & $7.64 \pm 1.79$ & $0.007 \pm 0.003$ \\
DS-SSD & $6.77 \pm 0.87$ & $0.005 \pm 0.003$ & $8.81 \pm 1.56$ & $0.004 \pm 0.003$ \\
LS-dry & $2.00 \pm 0.33$ & $0.017 \pm 0.004$ & $2.42 \pm 0.33$ & $0.019 \pm 0.005$ \\
LS-75 & $1.76 \pm 0.26$ & $0.02 \pm 0.004$ & $2.77 \pm 0.45$ & $0.028 \pm 0.004$ \\
LS-SSD & $1.94 \pm 0.28$ & $0.02 \pm 0.004$ & $3.73 \pm 2.37$ & $0.02 \pm 0.005$
\end{tabular}

Table 4: Bond max stress and corresponding slip/crack opening recorded in P, DT, DS and LS series

\subsection{Tensile bond tests}

After photo-scanning, the overlay was poured on the substrate profile, in regard to specific moisture conditions, as discussed in Section 2.2. Specimens were cured under standard lab conditions for 28 days and then prepared for bond testing. Bond test results of few specimens that were not so representative to the average value were discarded.

From $\mathrm{P}$ series, it can be noted that higher saturation levels lead to higher tensile bond strength values, see Fig. 5a. By a visual examination of the 
cracking/debonding surface, P-dry-B series showed a clear failure in the overlay near to the interfacial zone. Such a condition was less pronounced for P-dry-A series, where failure often occurred in the substrate near to the interfacial zone, see Fig. 6. The reason could be that the more brittle nature of overlay B, as compared to overlay A, induced higher stress concentration along the interface, thus causing a failure in the overlay. However, this aspect explains the cracking/debonding pattern observed in P-dry-B series only partially, since in all other series with the same overlay no failure within the overlay was observed. Further analyses seem to confirm that the cracking/debonding pattern was rather related to both the moisture level and the fresh properties of the overlay. From a theoretical point of view, under dry conditions, the concrete substrate surface tends to adsorb water from the fluid overlay. A densification of the micro-structure in the interfacial zone is possible and overlay fills the asperity of the roughened interface [3] After a proper curing such an interfacial transition zone creates a bond between the substrate and the overlay. If too much water is removed from the overlay at the interface, the risk of insufficient hydration rises up, which leads to a weak bond. This effect is magnified in overlays with very low w/c ratio, as observed in P-dry-B series $(\mathrm{w} / \mathrm{c}$ ratio $=0.17)$ where the failure took place in the overlay. By increasing the moisture levels the concrete substrate surface adsorbs less water from the fluid overlay, so the hydration in the interfacial zone rises up and creates a stronger bond between substrate and overlay, to the point that in P-75-A, P-75-B, P-SSD-A and P-SSD-B series bond failure was observed in the substrate layer, near to the interface. In terms of strength a clear increase in magnitude was observed in P-75-A, P-75-B, P-SSD-A and $\mathrm{P}-\mathrm{SSD}-\mathrm{B}$ series. This increase was more pronounced in substrates overlaid by UHPFRC (overlay B), due to its higher sensitivity to the moisture level, as compared to HPFRC (overlay $\mathrm{A}, \mathrm{w} / \mathrm{c}$ ratio $=0.28$ ).

In order to confirm the fact that load eccentricity was properly prevented during pull-off tests, some series of specimens were prepared and tested under direct tensile conditions (Fig. 3b). In few direct tensile tests, failure occurred on the interface between substrate and steel plate glued to the specimen (substrate side). These results were, of course, not useful to characterize the tensile bond capacity, so they were discarded. However, for specimens successfully tested, results in Fig. 5b confirm a good agreement both between P-B series and DT-B series and P-dry-A series and DT-dry-A series, proving the reliability of the modified pull-off test. Convergence was less evident between P-75-A, P-SSD-A series and DT-75-A, DT-SSD-A series, whose direct 
tensile strengths were slightly lower, as compared to pull-off strengths. This could be due to the geometry of specimens in $\mathrm{P}$ series. In $\mathrm{P}$ series, the load can be transferred over a larger substrate area, as compared to that in DT series, which may possibly increase the strength of the substrate near to the interface, see Figs. $3 a$ and $3 \mathrm{~b}$.

\subsection{Direct shear bond tests}

For DS-A series, SSD conditions achieved the highest bond shear strength, even though similar strength values were also observed in both DS-dry-A and DS-75-A, see Fig. 7. This observation confirms that explained in 3.2. Since the $\mathrm{w} / \mathrm{c}$ ratio of overlay $\mathrm{A}$ is not critically low, see Table 1 , the hydration magnitude of the interfacial zone was high enough to lead similar bond strengths for any change of moisture levels. The same conclusions were partly confirmed in [3], even though in such a work some variables were different, e.g. shear test method and surface treatment. Instead, a different response was observed in DS-B series, where the development of shear strength increased with increasing the moisture level, as also observed in P-B series. Fig. 8 illustrates some examples of bond failure occurred in series investigated.

\subsection{Tension/Shear bond tests}

In order to quantify the coupling factor between mode I and mode II, all possible stress states encountered in the practice were detected via tension/shear tests, see Section 2.4. Interface was subjected to a fixed tensile load value, while shear load increased until the failure. Five combinations of different tensile stress ratios were investigated: no tensile load (only shear load), $25 \%$ of tensile bond strength, $50 \%$ of tensile bond strength, $75 \%$ of tensile bond strength, solely tensile load (without shear load). Fig. 9 shows the bond failure envelope for substrates repaired with overlay A and B, under dry, $75 \%$ and SSD conditions. Each point in the graph represents the result of one specimen. Both DS-75-A and LS-75-A series showed lower shear bond values, in comparison with other series. This phenomenon was further pronounced when the interface was also subjected to an increase of tensile load, reducing the loading bond capacity. In fact, results of TS-75-A series in Fig. 9 , confirmed a premature bond failure, for low increases of tensile loading ratios, as compared to TS-dry-A and TS-SSD-A series. All other series in Fig. 9 denotes higher strength values, which permitted to obtain a shape almost linear of the bond failure envelope. In particular, it was observed a linear decrease of bond in shear, or tension, as stress in tension, or shear, 
increases. It should be taken into account that high scatter of bond strength is expected, because of the high roughness profile of the interface provided by hydro-jetting [4, see Fig. 4. A linear regression function was adopted to correlate experimental data, including any change of tensile/shear loading ratio here investigated. Even though more complex shapes of the regression functions were analyzed, the coefficient of determination provided by the linear regression was considered high enough to calibrate the cohesive parameters presented in Section 4. In particular, the slope of the linear regression, pointed out in Fig. 9, depicts the average coupling factor magnitude between mode I and mode II. Not less important is also the influence of the moisture condition, which clearly affects the bond capacity. Experimental data reported in Fig. 9 denotes an extension of the bond failure region, as the moisture level increases, confirming the trend observed in both pull-off and direct shear tests, see Sections 3.2 and 3.3 .

\subsection{Lateral shear bond tests}

In the practice, the unbalanced shear stress near to discontinuities of the bonded overlay leads to the development of tensile stress, perpendicular to the interface. As a consequence, a peeling moment is generated and increases with the edge overlay thickness. In order to simulate the cracking/debonding pattern of such a practical phenomenon, lateral shear tests were carried out. Results are showed in Fig. 10. The load-slip behavior was clearly affected by both moisture conditioning and fresh properties of overlay, whose trend is similar to that seen in P series. In fact, LS-dry-B series showed a clear failure in the overlay near to the interfacial zone. Such a condition was less pronounced for LS-dry-A series, where the failure often occurred in the substrate near to the interfacial zone. The failure moved away from the overlay and reached the substrate near the interface, by increasing the moisture levels, as already seen in Fig. 6. Such an effect was more evident for LS-B series. A correlation between bond strength and roughness profile provided by hydrojetting was illustrated in Fig. 11. The bond strength was compared with the coefficient of variation of roughness profile (COV), expressed as the ratio between standard deviation and average value. It was observed that bond strength tends to slightly decrease with COV values higher than $6 \%$, for any moisture condition; such a threshold was hardly ever exceeded. It can be stated that the opposite trend of increase of strength observed in UT-A and UT-B series is casual, since most data points confirmed that the bond 

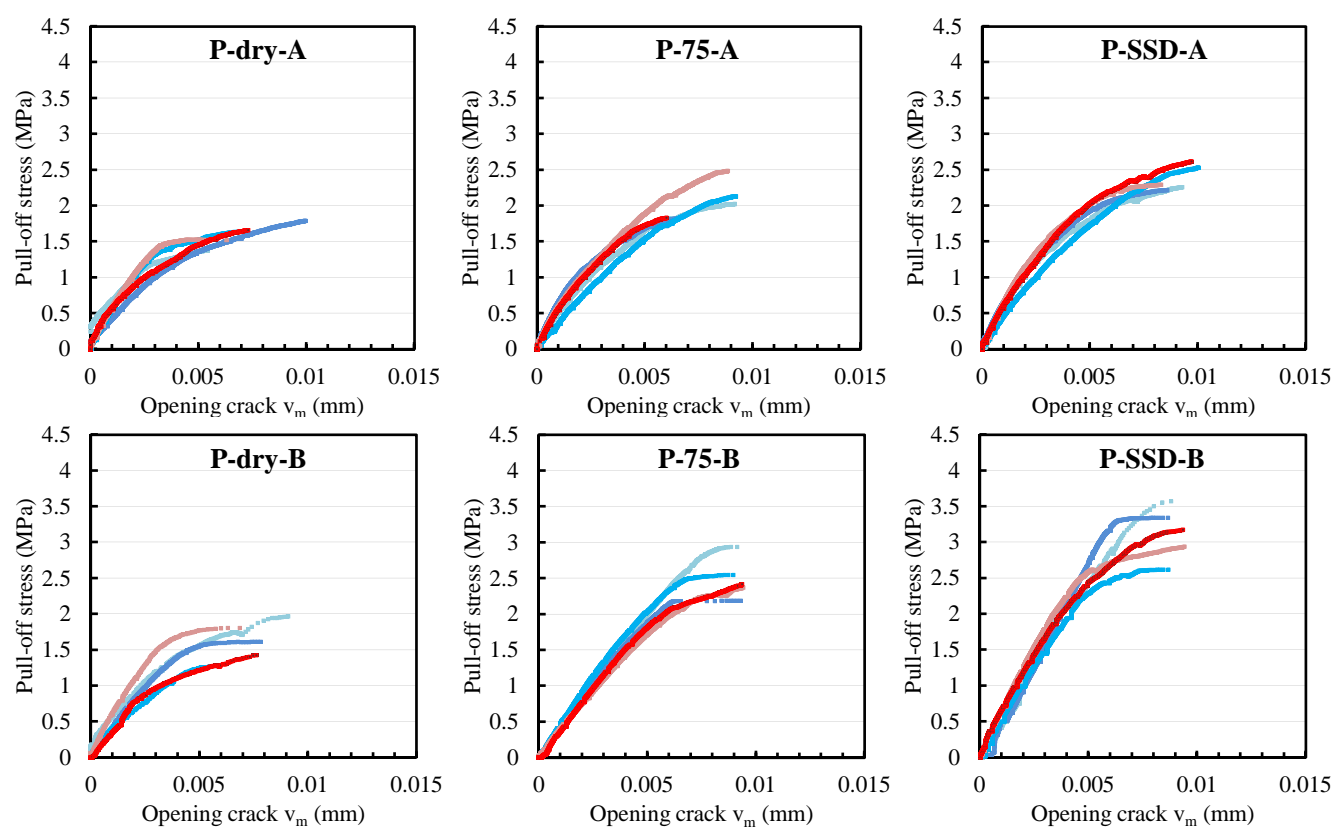

a
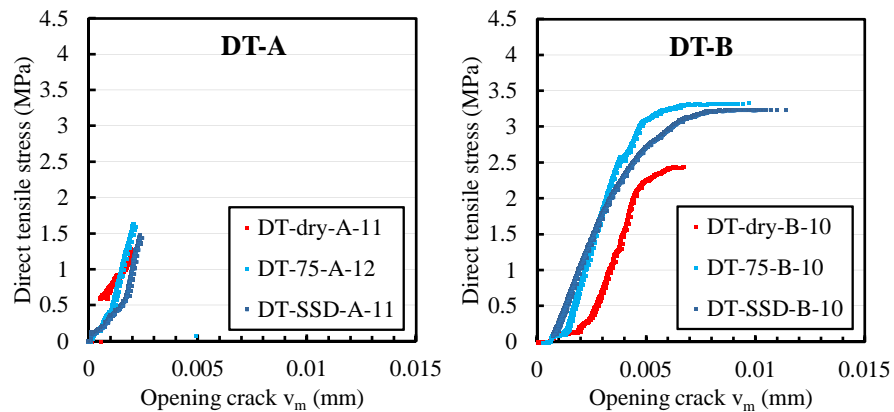

b

Figure 5: a): Pull-off test results; b) Direct tensile test results

strength is rather affected by both the moisture level and w/c ratio of the overlay, than the roughness COV.

Max bond stress and corresponding slip/crack opening reported in Figs. 5, 7 and 10 are listed in Table 4. 


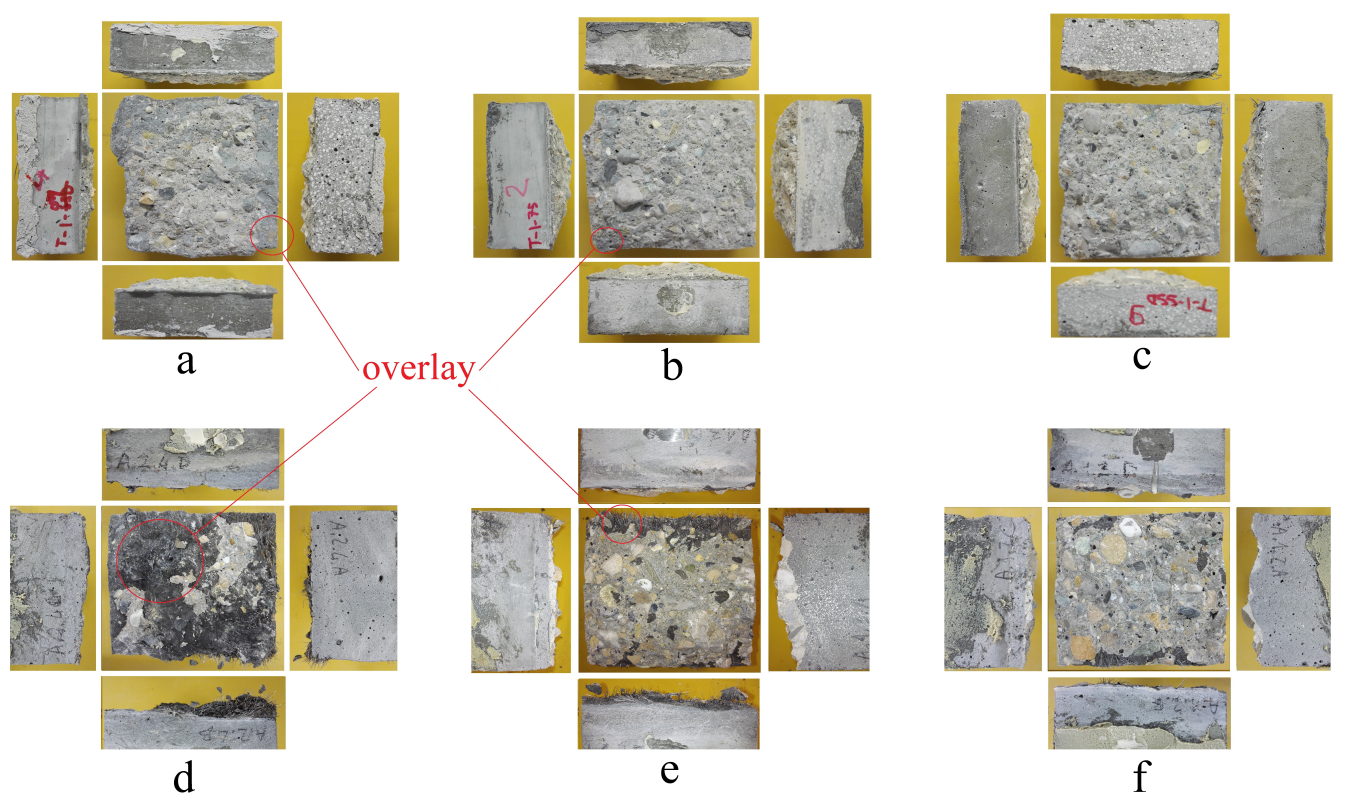

Figure 6: Cracking/debonding pattern observed after pull-off test a): P-dry-A series; b): P-75-A series; c): P-SSD-A series; d): P-dry-B series; e): P-75-B series; f): P-SSD-B series

\section{Cohesive model}

The cracking/debonding encountered in the practice near to discontinuities of the overlay was simulated by lateral shear bond tests on concrete slabs repaired by different overlays, see Section 3.5. In the experimental test, a concrete slab $200 \mathrm{~mm}$ thick was reinforced by $50 \mathrm{~mm}$ of HPFRC/UHPFRC. The edge side of the overlay was subjected to an incremental lateral shear load, until the cracking/debonding failure occurred along the interface zone. Experimental results confirmed that the majority of the deformability of the system "overlay-interface-substrate" is at the interface, so the material non-linearity of bonded layers was neglected to develop the cohesive model. In order to provide a generalized model, some bonded material properties should, however, be taken into account, in particular the elastic modulus, the shear modulus, the Poisson's ratio and the geometry of both bonded materials [18, 19, 20, 31, 55]. Consequently, the deformability of the overlay can be analytically represented with a Timoshenko beam of finite length, bonded to a rigid substrate. The beam of length $L$, with rectangular cross section of height $h$ and width $b$, is subjected to horizontal displacement $u_{L}$ imposed 

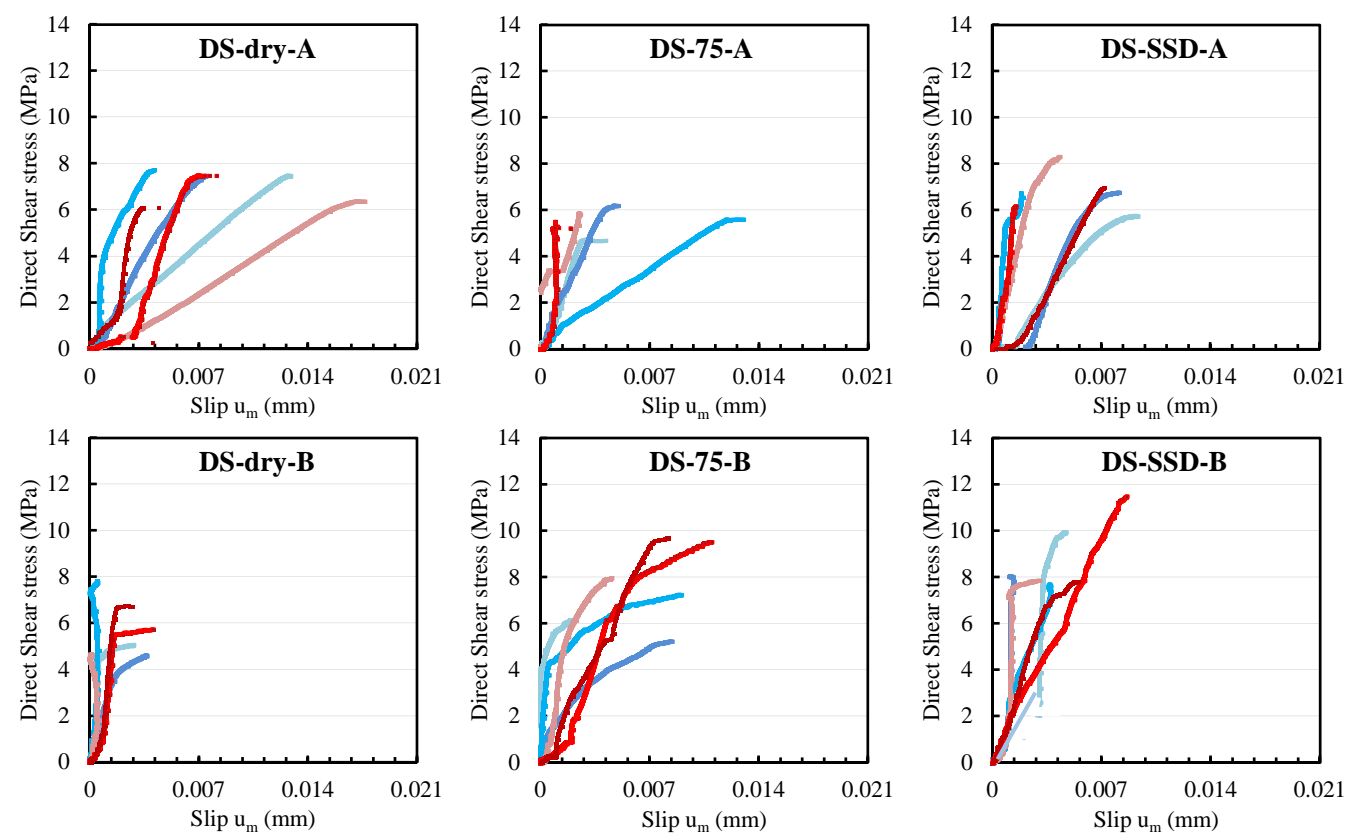

Figure 7: Direct shear test results

at the end of the beam. $u_{L}$ represents the slip measured at the interface in LS series (Figs. 3d, 8d). Axial forces are positive if rightward directed, shear forces are positive if upward directed, bending moments are positive if counterclockwise, as showed in Fig. 12. The equilibrium equations of the beam are:

$$
N^{I}+\tau=0, \quad T^{I}+q=0, \quad M^{I}-T+\tau \frac{h}{2}=0,
$$

where $N, T$ and $M$ are the internal forces applied at the beam cross section. $\tau$ and $q$ represent the shear and peeling tractions, respectively, which arise at the interface between the beam and the rigid support. Prime "I" denotes differentiation with respect to coordinate $x$. Kinematic assumptions for Timoshenko beam together with constitutive laws provide the following relations:

$$
\frac{M}{E I}=\varphi^{I}, \quad u^{I}=\frac{N}{E A}+\varphi^{I} \frac{h}{2}, \quad v^{I}=-\varphi+\frac{\chi T}{G A},
$$

where $E$ denotes the Young modulus of the beam, $A$ and $I$ are the area and 


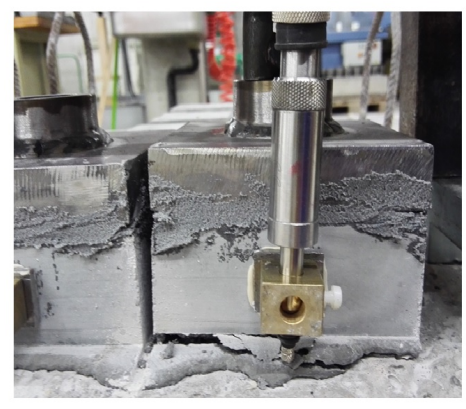

a

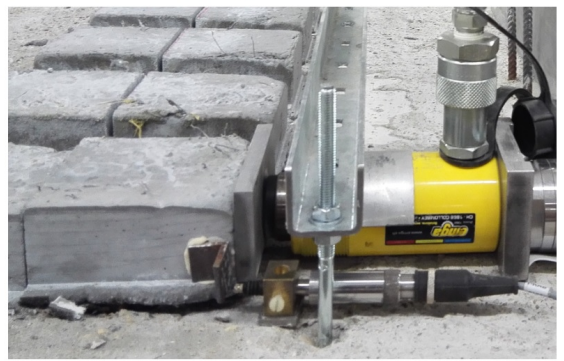

d

b
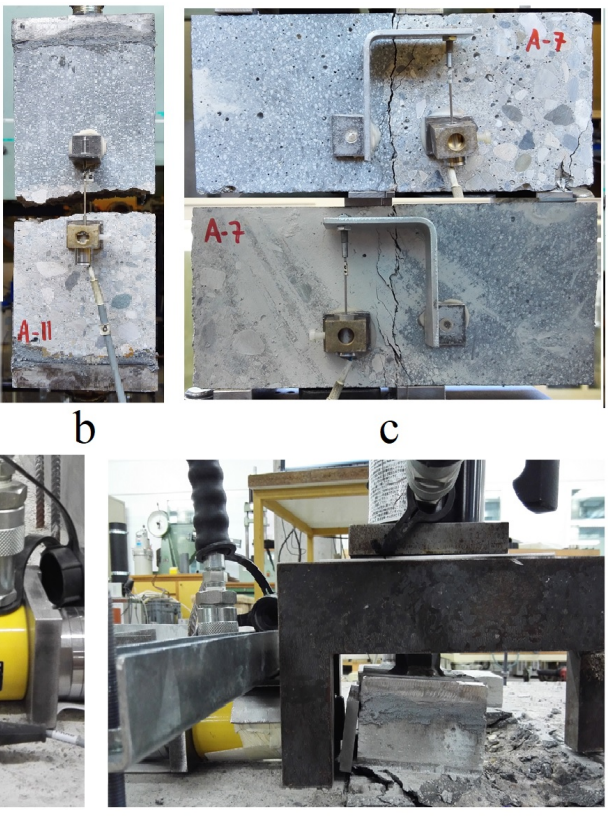

e

Figure 8: Bond test failures a): P series; b): DT series; c): DS series; d): LS series; e): TS series

the moment of inertia of the beam cross section respectively, $G$ represents the shear modulus of the beam, $\chi$ is the shear factor which, for a rectangular cross section and for plane stress condition, reads $\chi=6(1-\nu G / E) / 5, \nu$ is the Poisson ratio of the beam. $u(x)$ is the relative horizontal displacement between beam and rigid support at $y=h / 2$ (slip at the interface), $v(x)$ represents the relative vertical displacement between beam and the rigid support along the $y$ axis (crack at the interface), $\varphi(x)$ denotes the relative rotation of the beam cross section, positive if counterclockwise. The cross section of the beam is assumed to preserve its planarity after bending. The interface was modeled of a series of translational springs, which link substrate and overlay together. Vertical and horizontal springs represent mode I $(q(x)$ $v(x))$ and mode II $(\tau(x)-u(x))$, respectively. Once stress along the interface reach the peak of strength, the residual strength ensured by the interlocking mechanism is defined by a softening curve. Such a curve goes to zero when cracking/debonding spreads along the whole interface. This phenomenon concerns both mode I and mode II. Experimental results recorded in P and DS series, see Section 3, permitted to calibrate both the initial stiffness and 


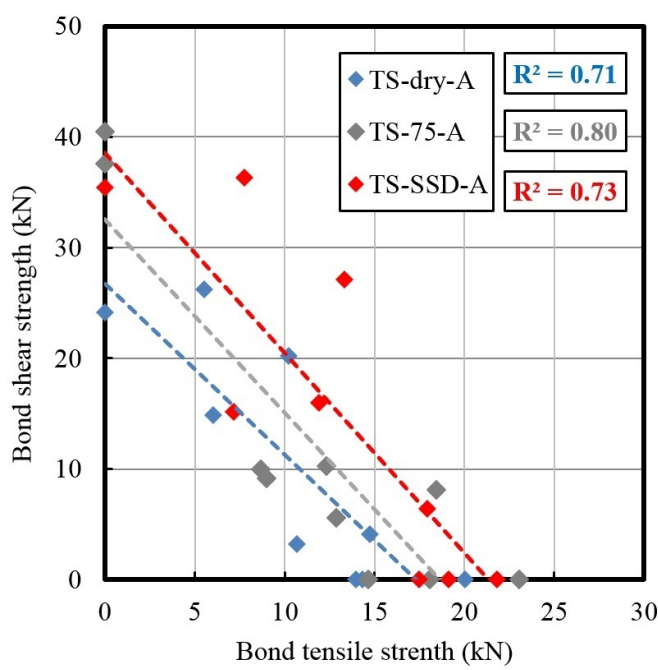

a

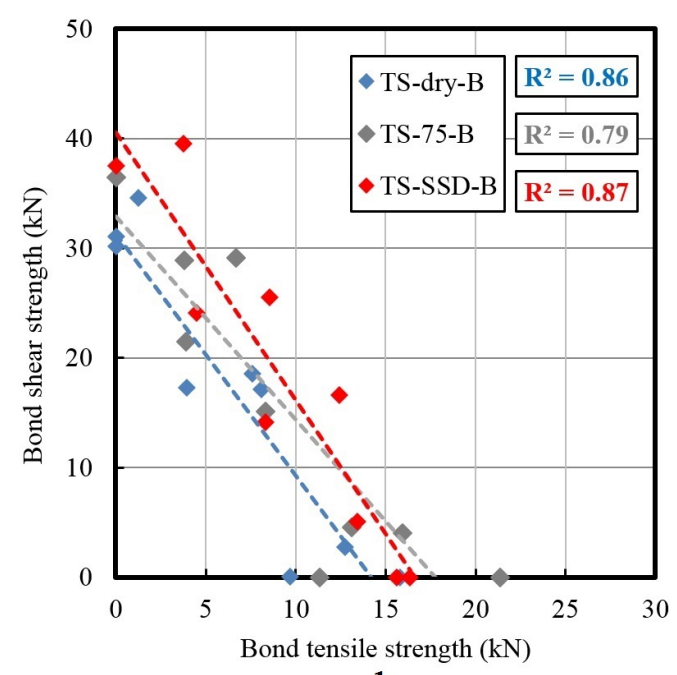

$\mathrm{b}$

Figure 9: Bond failure envelope for a): substrate overlaid by A; b): substrate overlaid by B
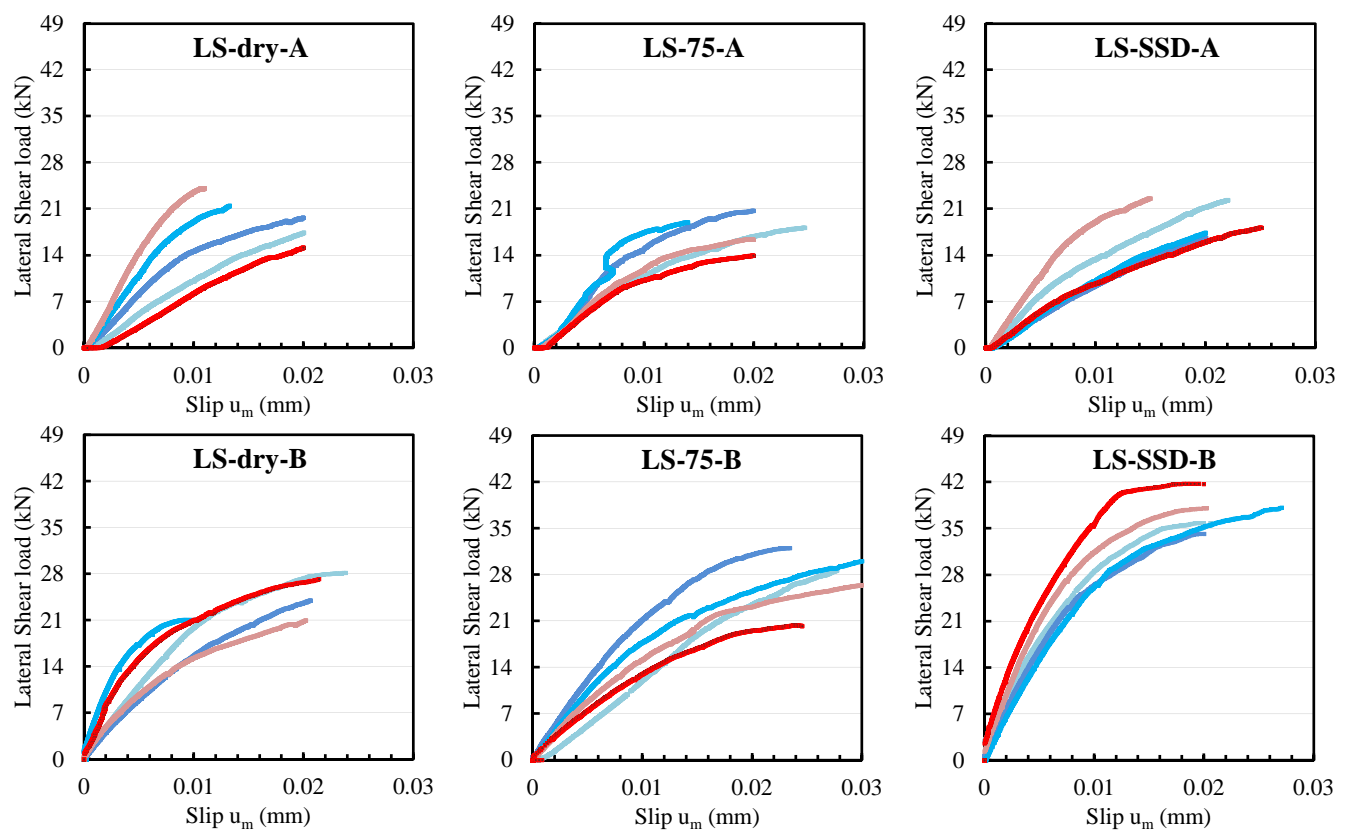

Figure 10: Lateral shear test results 

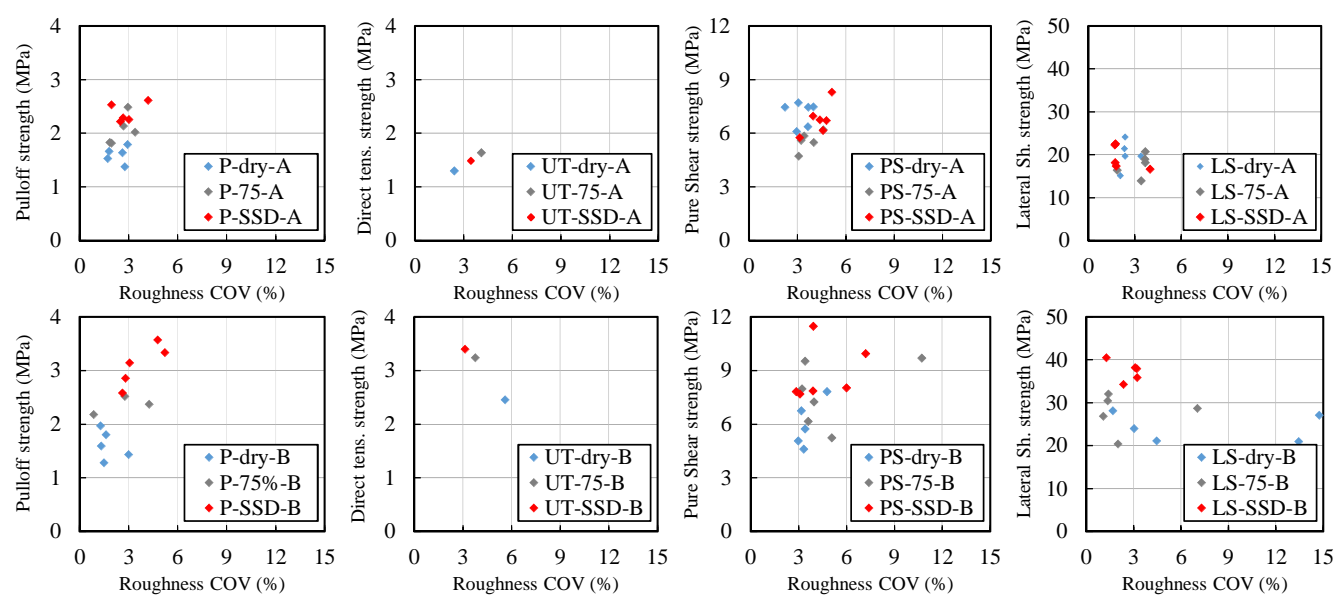

Figure 11: Correlation between bond strengths and roughness COV
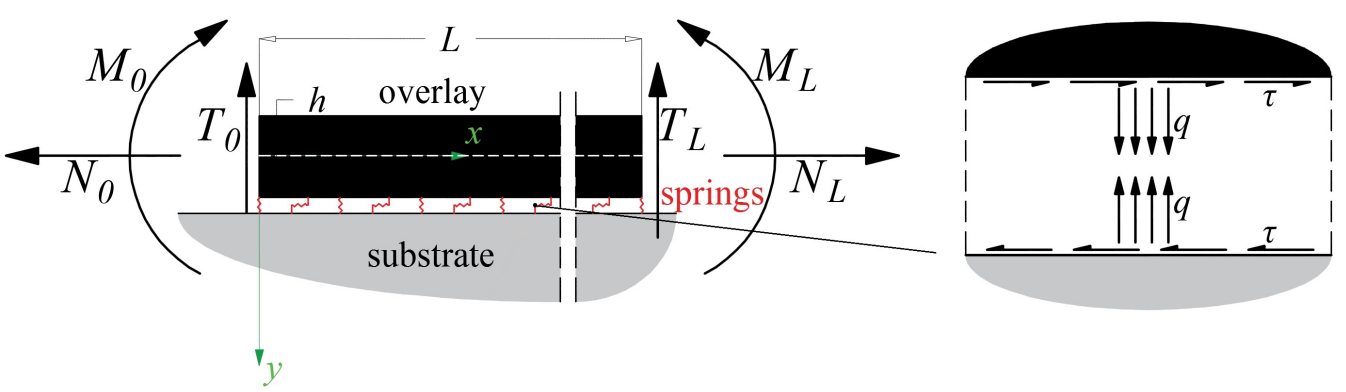

Figure 12: A Timoshenko beam (overlay) bonded to a rigid support (substrate) via translational springs

the peak of strength of both mode I and mode II. The missing information concerning the softening curve after peak were derived from few data found in Literature. In particular, Granju et al. (2004) [24] proposed a limiting value of opening $v_{\text {res }}$ beyond which there is no more interlocking in mode I, similar to the limit slip $u_{\text {res }}$ in mode II. As a first approximation it was assumed that $u_{\text {res }}=v_{\text {res }}$ equal to $0.05 \mathrm{~mm}$, as observed in [24], one of the few available research. By coupling experimental data presented in Section $3(\mathrm{P}$, DS and TS series) with those derived from the Literature, it was possible to fit a numerical function. This function was finally adopted to describe the 


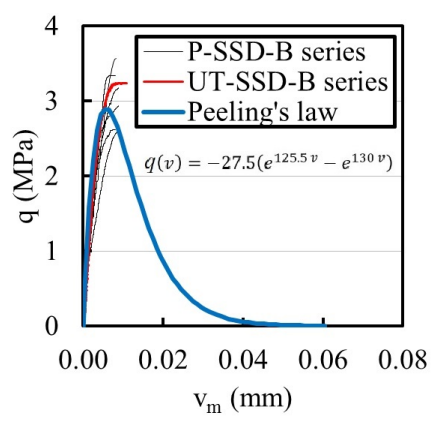

a

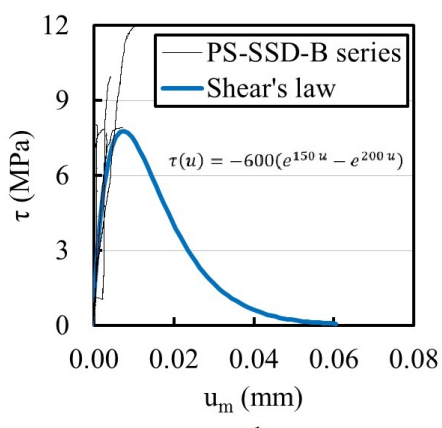

$\mathrm{b}$

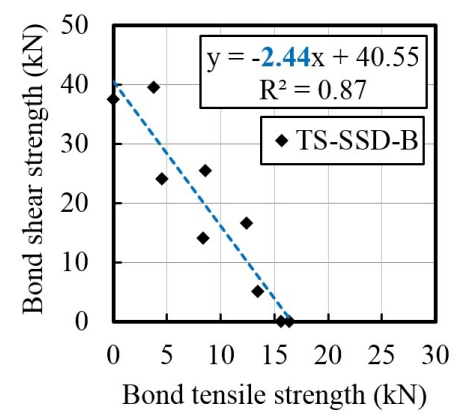

c

Figure 13: Parametrization of constitutive laws for a): mode I; b): mode II; c): coupling factor magnitude, for SSD-B series
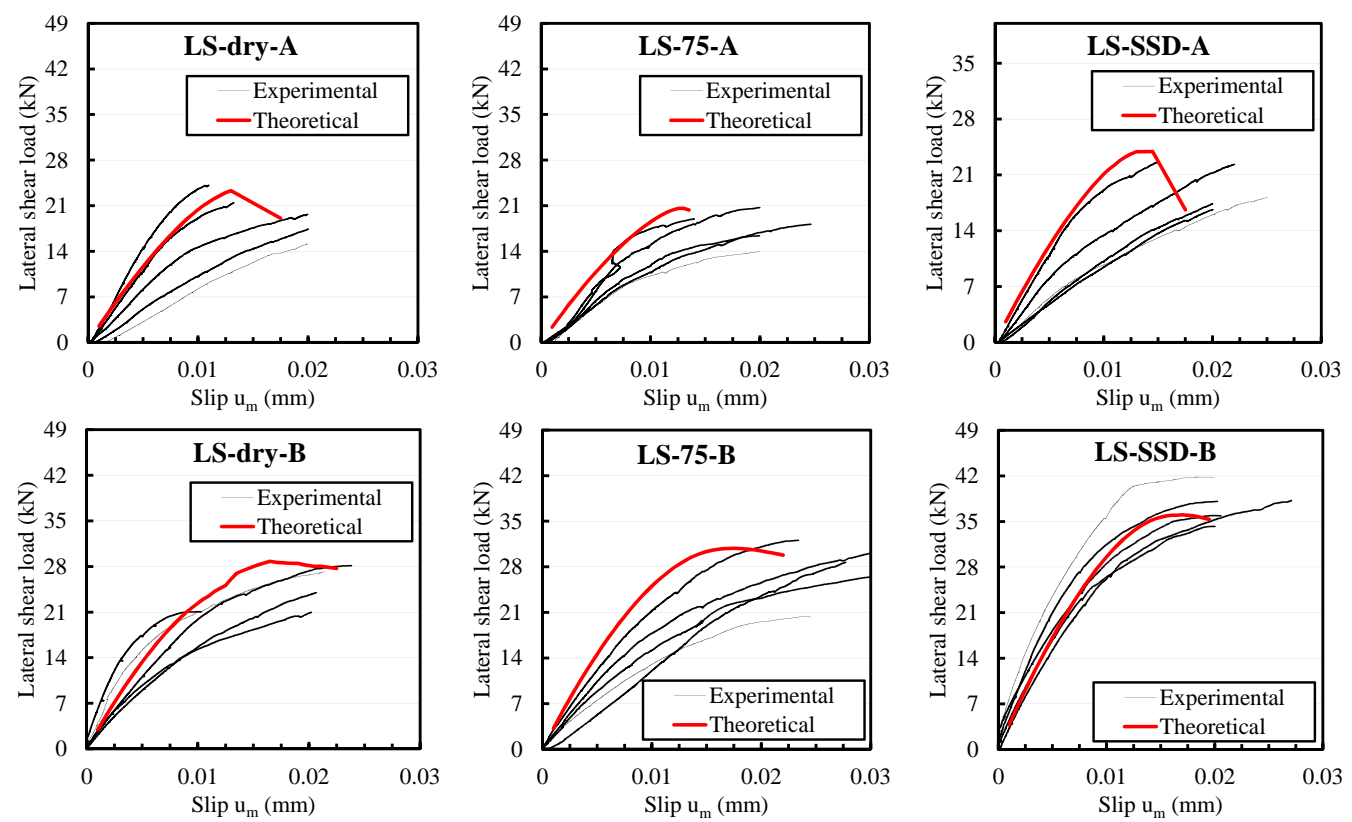

Figure 14: Comparison of bond loading capacity under mixed mode between experimental and theoretical data

${ }_{484}$ constitutive laws governing both mode I and mode II, see Equation 3.

$$
q(v)=a_{q}\left(e^{b_{q} v(x)}-e^{c_{q} v(x)}\right), \quad \tau(u)=a_{\tau}\left(e^{b_{\tau} u(x)}-e^{c_{\tau} u(x)}\right)-c q(v),
$$


where $a_{q}, b_{q}, c_{q}, a_{\tau}, b_{\tau}$ and $c_{\tau}$ are coefficients of the analytical relationships that best fit experimental curves; while $c$ is the coupling factor between mode I and mode II, provided from TS series. The latter represents the slope of the linear regression showed in Fig. 13. The equilibrium conditions of the beam read [31]:

$$
\begin{aligned}
& N(x)=N_{L}+\int_{x}^{L} \tau(s) d s, \quad T(x)=-T_{L}+\int_{x}^{L} q(s) d s, \\
& M(x)=M_{L}+T_{L}+\frac{h}{2} \int_{x}^{L} \tau(s) d s+\int_{x}^{L} q(s)(x-s) d s, \quad \text { for }|x| \leq L .
\end{aligned}
$$

In order to calculate the stress and kinematic fields at the interface under lateral shear load, a fourth-order ordinary differential equation system is defined by substituting (2) in (1):

$$
\left\{\begin{array}{l}
E A\left[u^{I I}(x)-\frac{h}{2}\left(-v^{I I I}(x)-\frac{\chi q^{I}(x)}{G A}\right)\right]+\tau(x) b=0 \\
E I\left(-v^{I V}(x)-\frac{\chi q^{I I}(x)}{G A}\right)+\tau^{I}(x) b \frac{h}{2}+q(x) b=0
\end{array}\right.
$$

In our case, no external dead force acts at the ends of the beam. Therefore, the following six boundary conditions are associated:

$$
\left\{\begin{array}{l}
u(x=L)=u_{L} \\
N(x=0)=0 \\
T(x=0)=0 \\
T(x=L)=0 \\
M(x=0)=0 \\
M(x=L)=0 .
\end{array}\right.
$$

Such a problem cannot be solved in a closed form. A computational code was used to provide a numerical solution, by increasing the lateral shear load, in order to reproduce the experience recorded in LS series. Fig. 14 confirms the reliability of the model. The theoretical curves could go further to the decreasing branch, as partially observed in LS-dry-A, LS-SSD-A, LS-dry$\mathrm{B}$ and LS-75-B series. However, their reliability over the limit of available experimental data could not be confirmed. 


\section{Conclusions}

In this work a cohesive model was developed to predict the loading bond capacity of retrofitted concrete structures, whose interface is subjected to mixed mode. The experimental investigation permitted to validate both the proposed model and highlight the different cracking/debonding patterns observed in the system "overlay-interface-substrate", by varying both the moisture conditions of the substrate prior to the application of the overlay and the properties of the latter.

In such a model, mode I (tension-crack), mode II (shear-slip) and their coupling factor were calibrated via bond tests specifically designed by authors. In particular, a modified pull-off and a direct shear devices were designed to calibrate the relationships of mode I and mode II, respectively. A tension/shear device was designed to calibrate the coupling factor between modes I and II. The results provided by the cohesive model showed a great agreement with the experimental data recorded by the mixed mode test. The testing system was designed to be man-portable and easy to use both in situ and in the lab. An increase of the load carrying capacity would permit to test interface longer than $100 \mathrm{~mm}$, in order to better reproduce the propagation of mixed stress along the interface of full scale rehabilitated concrete composite members.

A potential limit of the cohesive model is due to the assumption of the substrate as a rigid support, which needs more investigations in cases of higher thickness ratios between overlay and substrate.

Experimental data highlighted the influence of the moisture condition level on the development of high bond capacity, answering to the controversial opinions found in recent studies. In particular, dry conditions can be detrimental, for overlays with very low w/c ratios $(<0.2)$, which is typical for UHPFRC materials. It was also observed that in dry conditions the cracking/debonding pattern failed in the UHPFRC overlay. Detrimental effects were not observed for HPFRCC overlays, whose sensitivity to low moisture levels is reduced because of their higher $\mathrm{w} / \mathrm{c}$ ratios $(>0.2-0.3)$. However, SSD conditions should not be considered the best solution in all cases. If both moisture level and w/c ratio of the overlay are relatively high, the risk to develop a weak bond returns growing, since the excess of water along the interface increases the $\mathrm{w} / \mathrm{c}$ ratio of the fresh overlay reducing the development of high bond strength values. 


\section{Acknowledgments}

Authors gratefully acknowledge the financial support provided by HEIGVD. Financial support from the Italian Ministry of Education, University and Research (MIUR) in the framework of the Project PRIN 2017 " Modelling of constitutive laws for traditional and innovative building materials" (code 2017HFPKZY) is gratefully acknowledged.

\section{References}

[1] Al-Osta M, Isa M, Baluch M, Rahman M. Flexural behavior of reinforced concrete beams strengthened with ultra-high performance fiber reinforced concrete. Constr Build Mater 134, 2017, pp. 279-296.

[2] Austin S, Robins P, Pan Y. Shear bond testing of concrete repairs. Cement and Concrete Research, 29 (7), 1999, pp. 1067-1076.

[3] Bentz DP, De la Varga I, Muñoz JF, Spragg RP, Graybeal BA, S.Hussey DS, Jacobson DL, Jones SZ, LaManna JM. Influence of Substrate Moisture State and Roughness on Interface Microstructure and Bond Strength: Slant Shear vs. Pull-Off Testing. Cement and Concrete Composites, 87, 2018, pp. 63-72.

[4] Beushausen HD. Long-term performance of bonded concrete overlays subjected to differential shrinkage. PhD Thesis, University of Cape Town, South Africa, 2005, pp. 1-264.

[5] Beushausen H. The influence of concrete substrate preparation on overlay bond strength. Magazine of Concrete Research, 62 (11), 2010, pp. 845-852.

[6] Beushausen H, Alexander MG. Bond strength development between concretes of different ages. Magazine of Concrete Research 60, 2008, pp. 65-74.

[7] Bissonnette B, Courard L, Garbacz A, Vaysburd AM, Von Fay KF, Robertson B. Development of specifications and performance criteria for surface preparation based on issues related to bond strength. Final Report ST-2017-2886-1, U.S. Department of the Interior, 2017, pp. 1-198.

[8] Bissonnette B, Nuta A, Morency M, Marchand J, Vaysburd AM. Concrete repair and interfacial bond: Influence of surface preparation. In: Alexander 
MG, Beushausen HD, Dehn F, Moyo P, eds. Concrete Repair, Rehabilitation and Retrofitting II: 2nd International Conference - November 24-26, 2008, Cape Town, South Africa.

[9] Bissonnette B, Vaysburd AM, Von Fay KF. Moisture Content Requirements for Repair, Part 1: Concrete Repair Testing. Report Number MERL-2013-63, U.S. Department of the Interior, 2014, pp. 1-45.

[10] Bonaldo E, Barros JAO, Lourenço PB. Bond characterization between concrete substrate and repairing SFRC using pull-off testing. International Journal of Adhesion and Adhesives, 25 (6), 2005, pp. 463-474.

[11] Brühwiler E, Denarié E. Rehabilitation of concrete structures using Ultra-High Performance Fibre Reinforced Concrete. The Second International Symposium on Ultra High Performance Concrete. March 05-07, 2008, Kassel, Germany.

[12] Carloni C, Verre S, Sneed LH, Ombres L. Loading rate effect on the debonding phenomenon in fiber reinforced cementitious matrix-concrete joints. Composites Part B: Engineering 108, 2017, 301-314.

[13] ChunPing G, Guang Y, Wei S. Ultrahigh performance concreteproperties, applications and perspectives. Science China Technological Sciences, 58 (4), 2015, pp. 587-599.

[14] D'Ambrisi A, Feo L, Focacci F. Experimental analysis on bond between PBO-FRCM strengthening materials and concrete. Composites Part B: Engineering, 44 (1), 2013, pp. 524-532

[15] D'Ambrisi A, Feo L, Focacci F. Experimental and analytical investigation on bond between Carbon-FRCM materials and masonry. Composites Part B: Engineering, 46, 2013, pp. 15-20

[16] Delatte NJ, Wade DM, Fowler DW. Laboratory and Field Testing of Concrete Bond Development for Expedited Bonded Concrete Overlays. ACI Materials Journal, 2000.

[17] Delatte NJ, Williamson MS, Fowler DW. Bond strength development with maturity of high-early-strength bonded concrete overlays. American Concrete Institute, 97 (2), 2000, pp. 201-207. 
[18] Falope FO, Lanzoni L, Tarantino AM. Double lap shear test on steel fabric reinforced cementitious matrix (SFRCM). Composite Structures 201 (2018) 503-513.

[19] Falope FO, Lanzoni L, Tarantino AM. Modified hinged beam test on steel fabric reinforced cementitious matrix (SFRCM). Composites Part B 146, 2018, ,pp. 232-243.

[20] Farzad M, Shafieifar M, Azizinamini A. Experimental and numerical study on bond strength between conventional concrete and Ultra HighPerformance Concrete (UHPC). Engineering Structures 186, 2019, pp. 297-305.

[21] Godaire D, Von Fay KF, Gumina T. Bond quality of fiber reinforced polymer concrete strengthening systems. Report of US Department of the Interior, Materials Engineering and research Laboratory, 2005, pp.1-143

[22] Granju J-L. Debonding of thin cement-based overlays. Journal of Materials in Civil Engineering, 13 (2), 2001, pp. 114-120.

[23] Granju J-L. Thin bonded overlays: About the role of fiber reinforcement on the limitation of their debonding. Advanced Cement Based Materials, 4 (1), 1997, pp. 21-27.

[24] Granju JL, Sabathier V, Turatsinze A, Toumi A. Interface between an old concrete and a bonded overlay: debonding mechanism. Interface Science, 12 (4), 2004, pp. 381-388.

[25] Guingot L, Dekhil D, Soulier P. Strenghtening of hydraulic structures with uhpc. RIELM-fib-AFGC Int. Symposium on Ultra-High Performance Fibre-Reinforced Concrete, UHPFRC 2013 - October 1-3, 2013, Marseille, France.

[26] Hajar Z, Novarin M, Servant C, Grégory Généreux, Davy Przybla, Daniel Bitar. Innovative solution for strengthening orthotropic decks using UHPFRC: The Illzach bridge. RILEM-fib-AFGC Int. Symposium on Ultra-High Performance Fiber-Reinforced Concrete, UHPFRC 2013 - October 1-3, 2013, Marseille, France.

[27] Harris DK, Muøoz MAC, Gheitasi A, Ahlborn TM, Rush SV. The challenges related to interface bond characterization of ultra-high-performance 
concrete with implications for bridge rehabilitation practices. Adv Civil Eng Mater 4(2), 2014, pp.75-101.

[28] Kauw V, Dornbusch J. Optimierung der verwendung von hochdruckwasserstrahl-systemen (HDWS) bei der betonuntergrund-vorbereitung. Beton und Stahlbetonbau, 92 (6), 1997, pp. 140-155.

[29] Krtulovic-Opara N, Toutanj H. Infrastructural repair and retrofit with HPFRCCs. Paper presented at the proceeding of the Second International RILEM Workshop High Performance Fibre Reinforced Cement Composites 2, Ann Arbor, USA, June 11-14-1995.

[30] Lanzoni L, Nobili A, Tarantino AM. Performance evaluation of a polypropylene-based draw-wired fibre for concrete structures. Construct. Build. Mater. 28 (2012) 798-806.

[31] Lanzoni L, Radi E. A loaded Timoshenko beam bonded to an elastic half plane. International Journal of Solids and Structures 92-93 (2016), pp. 76-90.

[32] Lanzoni L, Tarantino AM. Damaged hyperelastic membranes. Int. J. NonLinear Mech. 60 (2014) 9-22.

[33] Lanzoni L, Tarantino AM. Equilibrium configurations and stability of a damaged body under uniaxial tractions. ZAMP Zeitsc. Angew. Math. Phys. 66(1) (2015) 171-190.

[34] Lanzoni L, Tarantino AM. A simple nonlinear model to simulate the localized necking and neck propagation. Int. J. NonLinear Mech. 84 (2016) 94-104.

[35] Li S, Geissert DG, Frantz GC, Stephens EJ. Durability and bond of highperformance concrete and repaired portland cement concrete. Project JHR 97-257, Joint Highway Research Advisory Council, University of Connecticut, 1997, pp. 1-232.

[36] Luković M, Ye G. Effect of moisture exchange on interface formation in the repair system studied by x-ray absorption. Materials, 9 (2), 2016, pp. $1-17$. 
[37] Mavar K, Skazlić M Influence of construction technology on the adhesion of remedial concrete. Gradevinar (Journal of the Croatian Association of Civil Engineers), 64, 2012, pp. 545-552.

[38] Nobili A, Lanzoni L, Tarantino AM. Experimental investigation and monitoring of a polypropylene-based fiber reinforced concrete road pavement. Construct. Build. Mater. 47 (2013) 888-895.

[39] Ono T. Application of ultra-high-strength fiber-reinforced concrete for irrigation channel repair works. In: Toutlemonde F, Resplendino J, eds. Designing and building with UHPFRC- State of the Art and Development. 2011, pp. 541-552.

[40] Savino V, Lanzoni L, Tarantino AM, Viviani M. Tensile constitutive behavior of high and ultra-high performance fibre-reinforced concretes. Construction and Building Materials 186, 2018, pp. 525-536.

[41] Savino V, Lanzoni L, Tarantino AM, Viviani M. Simple and effective models to predict the compressive and tensile strength of HPFRC as the steel fiber content and type changes. Composites Part B 137, 2018, pp. 153-162.

[42] Savino V, Lanzoni L. Tarantino AM, Viviani M. An extended model to predict the compressive, tensile and flexural strengths of HPFRCs and UHPFRCs: Definition and experimental validation. Composites Part B 163, 2019 pp. 681-689.

[43] Silfwerbrand J. Evaluation of tests on water-jet equipment. BHR Group, Jetting Technology, 2000, pp. 113-119.

[44] Silfwerbrand J. Improving concrete bond in repaired bridge decks. Concrete International, 12 (9), 1990, pp. 61-66.

[45] Silfwerbrand J. Shear bond strength in repaired concrete structures. Materials and Structures, 36 (6), 2003, pp. 419-424.

[46] Silfwerbrand J, Beushausen H, Courard L. Bond. In: Bissonnette B, Courard L, Fowler DW, Granju JL, eds. Bonded Cement-Based Material Overlays for the Repair, the Lining or the Strengthening of Slabs or Pavements, RILEM State-of-the-Art Report Technical Committee 193-RLS. 2011, pp. 51-79. 
[47] Tarantino AM. Equilibrium paths of a hyperelastic body under progressive damage. Journal of Elasticity, 114, 2014, pp. 225-250.

[48] Tayeh BA, Bakar BA, Johari MM, Voo YL. Mechanical and permeability properties of the interface between normal concrete substrate and ultra high performance fiber concrete overlay. Constr Build Mater 36, 2012,pp.538-548.

[49] De la Varga I, Muñoz JF, Bentz DP, Graybeal BA. Effect of the interface moisture content on the bond performance between a concrete substrate and a non-shrink cement-based grout. 2015 National Accelerated Bridge Construction Conference, Miami, FL, 2015.

[50] Vaysburd AM, Bissonnette B, Thomassin MM, Von Fay KF, Harrell SJ, Robertson B. Concrete substrate moisture requirements for effective concrete repairs. Report ST-2016-2886-01, 2016, pp. 1-65.

[51] Vaysburd AM, McDonald JE. An evaluation of equipment and procedures for tensile bond testing of concrete repairs. Technical Report REMRCS-61, US Army Corps of Engineers, Waterways Experiment Station, Vicksburg, Mississippi, USA, 1999.

[52] Vaysburd AM, Sabnis G, McDonald JE. Interfacial bond and surface preparation in concrete Repair. Indian Concrete Journal, 75 (1), 2001, pp. $27-33$.

[53] Walter R, Stang H, Olesen JF, Gimsing NJ. Debonding of FRC composite deck bridge. Brittle Matrix Composites 7, Proceedings of an International Symposium, Warsaw, October, Woodhead Publishing, 2003, pp. 191-200.

[54] Warner J, Bhuyan S, Smoak WG, Hindo KR, Sprinkel MM. Surface preparation for overlays. Concrete International, 20 (5), 1998, pp. 43-46.

[55] Yin H, Shirai K, Teo W. Numerical model for predicting the structural response of composite UHPC-concrete members considering the bond strength at the interface. Composite Structures 215, 2019, pp. 185-197.

[56] Standard test method for pull-off strength of coating using portable adhesion testers. ASTM D4541-17, 2002. 
[57] Testing concrete. Recommendations for the assessment of concrete strength by near-to-surface tests. BS 1881-207, 1992.

[58] CNR-DT 204. Guidelines for design, construction and production control of fiber reinforced concrete structures. National Research Council of Italy, 2006 .

[59] EN 206-1. Specification, performance, production and conformity - Part 1. 1990 .

[60] EN 1542 Products and systems for the protection and repair of concrete structures - measurement of bond strength by pull-off, 1999.

[61] EN 1992-1-1. General rules and rules for buildings - Design of concrete structures - Part 1-1. 2004.

[62] EN 13412. Products and systems for the protection and repair of concrete structures - Determination of modulus of elasticity in compression,2006.

[63] EN 12350-2. Testing fresh concrete. Slump-test . 2009.

[64] EN 12350-5. Testing fresh concrete. Flow table test . 2009.

[65] EN 12350-8. Testing fresh concrete. Self-compacting concrete. Slumpflow test . 2010.

[66] EN 12390-3. Testing hardened concrete - compressive strength of test specimens. 2003.

[67] The Federal Highway Administration. Ultra-High Performance Concrete : A State-of-the Art Report for the Bridge Community. Publication No. FHWA-HRT-13-060, McLean, VA 22101-2296, 2013 


\section{List of Figures}

$1 \quad$ Specimens for a): direct shear and direct tensile tests; b): pull-off test; c): tension/shear and lateral shear tests $\quad \ldots$. . . 7

2 a): specimens before hydro-jetting; b): hydro-jetting operation; c): specimens after hydro-jetting . . . . . . . . . . 8

3 a): Pull-off test; b): Direct tensile tests; c): Direct shear test; d): Lateral shear test; e): Tension/shear test . . . . . . . . . . 11

4 Roughness profile scanned for a given series (measuring in me-

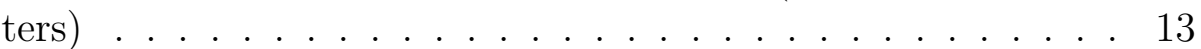

5 a): Pull-off test results; b) Direct tensile test results . . . . . . 17

$6 \quad$ Cracking/debonding pattern observed after pull-off test a): Pdry-A series; b): P-75-A series; c): P-SSD-A series; d): P-dryB series; e): P-75-B series; f): P-SSD-B series . . . . . . . 18

7 Direct shear test results $\ldots \ldots \ldots \ldots$

8 Bond test failures a): P series; b): DT series; c): DS series; d): LS series; e): TS series . . . . . . . . . . . . . . 20

$9 \quad$ Bond failure envelope for a): substrate overlaid by A; b): substrate overlaid by B. . . . . . . . . . . . . . . . . . . . 21

10 Lateral shear test results . . . . . . . . . . . . . . . . . 21

11 Correlation between bond strengths and roughness COV . . . 22

12 A Timoshenko beam (overlay) bonded to a rigid support (substrate) via translational springs . . . . . . . . . . 22

13 Parametrization of constitutive laws for a): mode I; b): mode II; c): coupling factor magnitude, for SSD-B series . . . . . . . 23

14 Comparison of bond loading capacity under mixed mode between experimental and theoretical data . . . . . . . . . 23 


\section{CONFLICT OF INTEREST}

The authors declare that the present work has been realized in compliance with the Ethical Standards.

This study was funded by the aforementioned grant only.

Conflict of Interest: The authors declare that they have no conflict of interest. 